\title{
Production, Hidden Action, and the Payment System
}

\author{
Chao $\mathrm{Gu}$ \\ University of Missouri \\ Mark Guzman \\ University of Reading \\ Joseph H. Haslag* \\ University of Missouri
}

March 15, 2010

\begin{abstract}
In this paper, we study a model economy that can account for the distribution of payments within a day. In our model, debtors choose when to arrive at the settlement location. Concomitant with choosing their arrival, debtors are making a production decision. We assume there is a cost to arriving early; that is, late-arrival is associated with a technology that dominates early arrival/production. Second, we treat the debtor's choice as hidden from creditors. We derive conditions under which the planner allocates production to each type of agents. In the decentralized setting, there is a nonarbitrage condition that is consistent with a positive intraday rate. The central bank may be able to implement the planner's allocation with a proper intraday interest rate. In some cases, the optimal intraday rate is positive.
\end{abstract}

Keywords: Friedman rule; discount window policy; payment system, intraday rate, settlement risk

JEL classification: E31; E51; E58.

${ }^{*}$ Corresponding author. Department of Economics, University of Missouri, Columbia, MO 65211; E-mail: haslagj@missouri.edu, Tel: (1-573) 882-3483, Fax: (1-573) 882-2697.

${ }^{\dagger}$ We wish to thank Morten Bech, Paula Hernandez, Todd Keister, Antoine Martin, Jamie McAndrews, David Mills, Erwan Quintin, the referee, and seminar participants at Texas A\&M University, Southern Methodist University, Federal Reserve Bank of New York, Federal Reserve Bank of Dallas and Missouri Economics Conference for helpful comments on earlier drafts of this paper. 


\section{Introduction}

In his seminal paper, Freeman [7] examined a model economy in which settlement risk is present. In Freeman's overlapping generations framework, a debtor borrows to consume when young and settles with the creditor when old. Settlement risk arises because there is a locational shock; debtors and creditors may not settle directly because their arrivals and departures are non-synchronous. This locational friction is the source of liquidity problem in Freeman's model: creditors leaving before their debtors arrive will seek to sell their IOUs in the resale market to creditors who have already been paid. If too few creditors have been paid, there is too little liquidity to pay par value on the IOUs and the early-leaving creditors suffer. With central bank liquidity provision, full insurance is achieved and the equilibrium in the decentralized market is the efficient allocation. ${ }^{1}$

The purpose of this paper is to extend Freeman's analysis in two specific areas. First, we develop a model economy in which the distribution of settlements is endogenously determined. ${ }^{2}$ The implication is that we can account for an endogenous, nondegenerate distribution of settlements within the day. Debtors choose when they will arrive at the settlement location - either in the morning or in the afternoon - by choosing when they will produce.

\footnotetext{
${ }^{1}$ Others have asked whether the central bank's discount window is necessary. Green [10] showed that the central bank's discount window was not necessary to solve the liquidity problem. The efficient allocation could be implemented by using private money could instead of central bank money. Mills [16] solved a mechanism design problem, demonstrating the equivalence between Freeman's economy with an active discount window and an economy in which perfect record keeping exists. Thus, the liquidity problem is a by-product of imperfect record keeping.

${ }^{2}$ Note that the average daily volume settled through Fedwire and CHIPs is $\$ 7.3$ trillion. The Federal Reserve has voiced concern about the volume of large payments settled late in the day. Operational risk is heightened by increasing the potential magnitude of liquidity dislocation (see [2]). Armantier et al. [2] document that, on average, twenty percent of the payments are settled before $1 \mathrm{pm}$ with the remaining eighty percent being settled after $1 \mathrm{pm}$.

Angelini [1] considers a framework in which there is a network externality that induce banks to delay settlement. He studies this problem in a partial equilibrium framework.
} 
(Hereafter, debtors will be identified as morning producers or afternoon producers according to their production decision.) In our model, young debtors offer IOUs to creditors to obtain inputs for the production process. The production decision is a hidden action so that the creditor cannot offer one contract to morning producers and another to afternoon producers. Further, we assume that for a given quantity of inputs, afternoon production will generate a larger quantity than morning production. In the decentralized economy, equilibrium consists of both morning and afternoon production. In equilibrium, there is a nonarbitrage condition. The marginal debtor is indifferent between morning and afternoon production because morning producers receive capital gains on IOUs purchased in the resale market. Indeed, the capital gains exactly offset the higher returns that come with afternoon production. So, some measure of producers are willing to produce in the morning, knowing that the combination of morning production returns and capital gains compensates them for eschewing afternoon production. The intraday return on IOUs is positive and there is a nondegenerate distribution of settlements.

Second, Freeman's policy involves buying the IOUs from morning-leaving creditors at face value and having the afternoon-arriving debtors settle the IOUs held by the central bank. The intraday discount window loans are offered at zero interest. The zero intraday rate is optimal in one version of our model. In particular, Freeman-type creditors are those whose consumption needs are unrelated to their locational shock. For these creditors, afternoon goods are perfect substitutes for morning goods. For this model economy, the efficient production schedule has zero morning production. In the absence of a discount window, the equilibrium in the decentralized economy does not achieve the optimal allocation. By setting the intraday rate at zero, the central bank eliminates capital gains in the IOU resale market. 
It follows that the equilibrium distribution of settlements is degenerate with all settlements occurring in the afternoon.

We further extend the analysis to consider an economy in which the creditor's locational shock coincides with a consumption shock. More specifically, creditors who leave the settlement location in the morning derive utility from consuming in the morning. To these creditors, afternoon goods are no longer perfect substitutes for morning goods. In this way, we consider the role of time-sensitive consumption opportunities. With concomitant location and consumption shocks, the planner's production plan will have to take into account whether endowments are large enough to provide full insurance to morning consumers. If the economy's endowments are large enough, no morning production occurs in the planner's allocation. A zero intraday interest rate can implement the planner's allocation. If the economy's endowments are too small, then a positive intraday rate is necessary; otherwise, the morning-leaving creditors' intertemporal marginal rate of substitution will exceed the morning-producer's marginal product of the capital at a zero intraday rate. Combined with a tax-transfer policy, a positive intraday rate can implement the efficient allocation provided there is no morning production. However, a positive intraday rate cannot achieve the efficient allocation if morning production is positive. In this version of the model economy, the intraday rate appears in both the morning producers' and the creditors' intertemporal decisions. For creditors, the intraday rate is the price of morning consumption relative to the afternoon consumption and is positive when the marginal product of the morning good is less than the marginal product of the afternoon good. One policy tool, in general, cannot simultaneously correct two (efficiency) conditions.

The paper is organized as follows. We describe the economic environment in Section 2. 
In Section 3, we define and characterize the equilibrium in the decentralized market. The planner's allocation is characterized in Section 4. Government policies that will implement the planner's allocation are derived in Section 5. In Section 6, we consider a modified economy in which morning goods and afternoon are imperfect substitutes. A brief summary and conclusions are presented in Section 7 .

\section{The physical environment}

We consider a modified version of the payment system model developed by Freeman [7]. The key difference is that young debtors acquire factor inputs from creditors. The production finances old-age consumption by debtors. The production schedule also determines when the debtors arrive to settle their IOUs.

Time and location: There is an infinite sequence of time periods. Dates are indexed by $t=1,2, \ldots$. At each date $t$, there are two subperiods, called morning and afternoon. There are a large number of paired islands distributed around a central island. Each island pair consists of a creditor island and a debtor island. On the central island, there is an enforcement authority that costlessly enforces all contracts. In addition, a monetary authority exists on the central island.

Agents: At the beginning of each period, there is a continuum of measure one of two-period lived agents born on each island. Agents born in a creditor (debtor) island are called creditors (debtors). At date $t=1$, there are a continuum of both creditors and debtors who live only one period, hereafter referred to as the initial old.

Endowments: Young debtors are endowed with $x$ units of a perishable island-specific con- 
sumption good. Young creditors are endowed with $y$ units of a perishable island-specific consumption good. To abuse notation a little bit, we also call debtor's and creditor's endowed goods good $x$ and good $y$, respectively. The initial old debtors are endowed with good $x$, and the initial old creditors are endowed with $m_{0}$ units of fiat money.

Production technology: There are two technologies available to young debtors. In both cases, a technology converts good $y$ at one-to-one rate into capital, producing goods. With $k$ units of date- $t$ capital, the morning production technology converts $f\left(k_{t}\right)$ into date- $t+1$ units of goods available in the morning. Alternatively, the afternoon-production technology, denoted $F\left(k_{t}\right)$, transforms $k$ units of date- $t+1$ goods into the afternoon good. Note that for a given finite input $k_{t}$, the production of the afternoon good strictly dominates the morning good; that is, $F\left(k_{0}\right)>f\left(k_{0}\right)$ for any $k_{0}>0$. We assume that the functions $f(k)$ and $F(k)$ are strictly increasing, strictly concave. ${ }^{3}$

Preferences: For a creditor born at date $t$, lifetime welfare is represented by a utility function $u\left(y_{1 t}^{c}, x_{2 t+1}^{c}\right)$, where $y_{1 t}^{c}$ is his consumption of good $y$ in his first period of life and $x_{2 t+1}^{c}$ is his consumption of good $x$ in his second period of life. Creditors learn which islandspecific debtor good they want when old. For a debtor born at date $t$, lifetime welfare is described by $v\left(x_{1 t}^{d}, x_{2 t+1}^{d}\right)$, where $x_{1 t}^{d}$ and $x_{2 t+1}^{d}$ are his consumption of good $x$ in his first and second periods of life, respectively. Both utility functions are separable, strictly increasing, strictly concave, and satisfy the Inada condition in both arguments.

Travel and trade patterns: For each date $t \geq 0$, a young debtor starts by travelling to the paired creditor island. He wants to purchase good $y$ from the young creditors, using the

\footnotetext{
${ }^{3}$ Freeman [9] specifies a model in which production is present. There is no distinction between morning and afternoon production in Freeman's model.
} 
input in production. As young creditors do not derive utility from debtor's good and the young debtor does not have money, the young debtor offers a debt contract, called an IOU, to the young creditors in exchange for a quantity of the $y$ good. The IOU is settled next period when old debtors arrive on the central island. After obtaining good $y$, the debtor returns to his home island and starts to produce using either the morning or the afternoon production technology. Later in the period, he sells some of his endowed good $x$ in exchange for fiat money to the old creditors who are randomly relocated to his island and to the old debtors who return to their home island. He uses fiat money in the next period to settle IOUs or to buy goods from the young generation.

Young debtors are now divided between being morning producers and afternoon producers. Let $\lambda$ be the measure of debtors choosing to be morning producers, while $1-\lambda$ is the measure of debtors choosing to be afternoon producers. In the next period, an old debtor travels to the central island to settle IOUs in the morning (afternoon) if he is a morning (afternoon) producer. After settling IOUs, the old debtor returns to his home island. No one can observe the young debtor's production choice. The production choice is publicly observed next period when the debtor arrives to settle the IOU.

A young creditor stays on his home island. He sells some of his endowed good to the young debtors and obtain IOUs. He travels to the central island in the next morning to settle the IOUs. Let $1-\alpha$ denote the probability that the old creditor has to leave the central island by noon (morning-leaving creditors). So, $\alpha$ is the probability that the old creditor stays until the afternoon (afternoon-leaving creditors). When leaving the central island, an old creditor is relocated randomly, following a uniform distribution, to a debtor island. This relocation identifies the type of date- $t+1$ good $x$ that gives utility to the old creditors. 
IOU contract: An IOU contract specifies the nominal value of the debt. It is expected to be settled at par in the next period (either morning or afternoon) on the central island. ${ }^{4}$ IOUs can be redeemed by either fiat money or real goods. At the time the IOU is issued, creditors know $\alpha$, the morning departure rate for old creditors, and take the believed value of $\lambda$ as given.

IOU resale market: When the morning-leaving creditors leave the central island, the IOUs issued by the afternoon producers have not been redeemed yet. The morning-leaving creditors can sell the unredeemed IOUs in a resale market. Potential buyers are those arriving at the central island in the morning and leaving during the afternoon subperiod; that is, afternoon-leaving creditors and morning producers.

\section{The decentralized economy}

\subsection{Debtor's problem}

All markets in our model are competitive. A young debtor compares the lifetime utilities from producing the morning good and the afternoon good given the goods prices, the resale price of the loan, and his believed measures of morning and afternoon producers. Let the lifetime utilities of a morning producer and an afternoon producer be represented by $v\left(x_{1 t}^{d}, x_{2 t+1}^{d}\right)$ and $v\left(x_{1 t}^{d *}, x_{2 t+1}^{d *}\right)$, respectively. Throughout our analysis, we will use the superscript " $*$ " to denote the quantities related to afternoon producers and afternoon-leaving creditors. The debtor's decision rule is straightforward: choose the technology that results in higher lifetime

\footnotetext{
${ }^{4}$ In the appendix, we also consider an IOU contract that is contingent on the timing of payments. All results in the text hold under such a contract.
} 
utility. If $v\left(x_{1 t}^{d}, x_{2 t+1}^{d}\right)=v\left(x_{1 t}^{d *}, x_{2 t+1}^{d *}\right)$, a debtor is indifferent to becoming either a morning or an afternoon producer. In this case, we assume that $\lambda$ represents the probability that a particular debtor will be a morning producer. By law of large numbers, $\lambda$ is also the measure of debtors that are morning producers and arrive on the central island to settle in the morning. In what follows, we describe a debtor's problem by the production choice.

\subsubsection{Morning producer}

A morning producer faces the following budget constraints when young:

$$
\begin{aligned}
p_{y t} y_{t} & =h_{t} \\
p_{x t} x & =p_{x t} x_{1 t}^{d}+m_{t}
\end{aligned}
$$

where $p_{x t}$ and $p_{y t}$ are the prices of goods $x$ and $y$ in period $t$, respectively, $m_{t}$ is the quantity of money acquired, the quantity of $y$ purchased by exchanging a nominal quantity of IOUs, denoted here by $h$. The morning producer transforms the $y$ good into capital, denoted $k$, at a one-for-one rate. When old, a morning producer arrives on the central island in the morning and faces the following budget constraint

$$
p_{x t+1} f\left(k_{t}\right)+m_{t}-h_{t}+b_{t+1}\left(1-\rho_{t+1}\right)=p_{x t+1} x_{2 t+1}^{d}
$$

$b_{t+1}$ is the par value of the IOUs he purchases in the date- $t+1$ resale market, and $\rho_{t+1}$ is the date- $t+1$ price of those IOUs. Note that under this constraint, debtors are capable of meeting their their old-age needs - consumption and settlement - through a combination 
of production, outside money and gains from IOU purchases. Money holdings by the old debtors need not be equal to IOU values. ${ }^{5}$

We form the monring producer's life-time budget constraint, obtaining

$$
\begin{aligned}
p_{x t+1} f\left(k_{t}\right)+p_{x t}\left(x-x_{1 t}^{d}\right)-p_{y t} k_{t}+b_{t+1}\left(1-\rho_{t+1}\right) & =p_{x t+1} x_{2 t+1}^{d} \\
x-x_{1 t}^{d} & \geq 0
\end{aligned}
$$

The morning producer faces a liquidity constraint in the loan resale market:

$$
p_{x t+1} f\left(k_{t}\right)+p_{x t}\left(x-x_{1 t}^{d}\right)-p_{y t} k_{t}-\rho_{t+1} b_{t+1} \geq 0
$$

which says the morning producer cannot borrow to purchase the IOUs.

A morning producer thus solves the following maximization problem

$$
\begin{array}{cc}
\max _{x_{1 t}^{d}, x_{2 t+1}^{d}, k_{t}, b_{t}} & v\left(d x_{1 t}^{d}, d x_{2 t+1}^{d}\right) \\
\text { s.t. } & (1)-(3) .
\end{array}
$$

The first-order conditions for the morning producers are

$$
\begin{aligned}
\left(x-x_{1 t}^{d}\right)\left(v_{1}\left(x_{1 t}^{d}\right)-v_{2}\left(x_{2 t+1}^{d}\right) \frac{p_{x t}}{p_{x t+1}} \frac{1}{\rho_{t+1}}\right) & =0 \\
f^{\prime}\left(k_{t}\right)-\frac{p_{y t}}{p_{x t+1}} & =0 \\
v_{2}\left(x_{2 t+1}^{d}\right) \frac{1-\rho_{t+1}}{p_{x t+1}}-\mu_{1} \rho_{t+1} & =0
\end{aligned}
$$

\footnotetext{
${ }^{5}$ To illustrate, suppose that the old debtor used production returns to settle debt, taking the money to the home island to purchase goods from young debtors. Money is used only to execute intergenerational transfers. The key point is some combination the real bills doctrine and fiat money coexists.
} 
where $\mu_{1}$ is the Lagrangian multiplier associated with an early producer's liquidity constraint. From the complementary slack condition, it follows that $\rho=1$ is satisfied if and only if the liquidity constraint in unbinding. If the liquidity constraint is binding, we obtain a case in which $\rho<1$.

\subsubsection{Afternoon producer}

If a debtor chooses to be an afternoon producer, his budget constraints when young are

$$
\begin{aligned}
p_{x t} x & =p_{x t} x_{1 t}^{d *}+m_{t}^{*} \\
p_{y t} k_{t}^{*} & =h_{t}^{*}
\end{aligned}
$$

When old, the debtor will not be able to trade in the loan resale market as he arrives late. The late producer's budget constraint when old is

$$
p_{x t+1} F\left(k_{t}^{*}\right)+m_{t}^{*}-h_{t}^{*}=p_{x t+1} x_{2 t+1}^{d *}
$$

The afternoon producer's life-time budget constraint is

$$
\begin{aligned}
p_{x t+1} F\left(k_{t}^{*}\right)+p_{x t}\left(x-x_{1 t}^{d *}\right)-p_{y t} k_{t}^{*} & =p_{x t+1} x_{2 t+1}^{d *} \\
x-x_{1 t}^{d *} & \geq 0
\end{aligned}
$$


So that an afternoon producer solves the following maximization problem:

$$
\begin{array}{cc}
\max _{x_{1 t}^{d *}, x_{2 t+1}^{d *}, k_{t}^{*}} & v\left(x_{1 t}^{d *}, x_{2 t+1}^{d *}\right) \\
\text { s.t. } & (5)-(6) .
\end{array}
$$

The first-order conditions for the afternoon producer's problem are:

$$
\begin{aligned}
\left(x-x_{1 t}^{d *}\right)\left(v_{1}\left(x_{1 t}^{d *}\right)-v_{2}\left(x_{2 t+1}^{d *}\right) \frac{p_{x t}}{p_{x t+1}}\right) & =0 \\
F^{\prime}\left(k_{t}^{*}\right)-\frac{p_{y t}}{p_{x t+1}} & =0
\end{aligned}
$$

\subsection{Creditor's problem}

A young creditor sells some of his endowments for IOUs. His budget constraint is

$$
l_{t}+p_{y} y_{t}^{c}=p_{y} y
$$

where $l_{t}$ denotes the nominal value of the IOUs issued at date- $t$ and carried over to the date- $t+1$ settlement location.

A young creditor faces uncertainty regarding the timing of departure from the central island when old. In the event that the creditor is a morning-leaver, settlement may not occur because some of his debtors may not arrive in the morning. If unsettled, the morning-leaver will offer the IOUs in the resale market. The budget constraint for an old morning-leaving creditor is: 


$$
\rho_{t+1}\left(1-a_{t}\right) l_{t}+a_{t} l_{t}=p_{x t+1} x_{2 t+1}^{c},
$$

where $a_{t}$ is the proportion of the IOUs that are issued at date $t$ and settled during the date- $t+1$ morning. It follows that $1-a_{t}$ is the proportion of IOUs sold in the resale market. With these resources, the old-age creditor can purchase units of the consumption good from debtors (either young or old or both). We assume that creditors can trade debtor islandspecific goods with each other on the central island. So if the IOUs are paid in goods, the creditors can convert it to his preferred debtor island-specific goods.

If, in contrast, the old creditor leaves in the afternoon, the creditor will settle all of his IOUs on the central island. He can also make arbitrage profits in the resale market by purchasing IOUs at discount from morning-leavers and settling with the afternoon-arriving debtors. This creditor's old-age budget constraint is:

$$
l_{t}+\left(1-\rho_{t+1}\right) q_{t+1}=p_{x t+1} x_{2 t+1}^{c *}
$$

where $q_{t+1}$ denotes the par value of the IOUs that an old afternoon-leaving creditor purchases in the date- $t+1$ resale market. The sum of the creditor's old-age resources are used to purchase units of the consumption good.

The liquidity constraint for an afternoon-leaving creditor is 


$$
a_{t} l_{t}-\rho_{t+1} q_{t+1} \geq 0
$$

Thus, a creditor solves the following life-time maximization problem:

$$
\begin{array}{cr}
\max _{l_{t}, q_{t}, y_{1 t}^{c}, x_{2 t+1}^{c}, x_{2 t+1}^{c *}}(1-\alpha) u\left(y_{1 t}^{c}, x_{2 t+1}^{c}\right)+\alpha u\left(y_{1 t}^{c}, x_{2 t+1}^{c *}\right) \\
\text { s.t. } & (8)-(11) .
\end{array}
$$

Substitute $y_{1 t}^{c}, x_{2 t+1}^{c}, x_{2 t+1}^{c *}$ using $l_{t}$ and $q_{t+1}$, the first-order conditions with respect to $l_{t}$ and $q_{t}$ for this problem are:

$$
\begin{gathered}
-u_{1}\left(y_{1 t}^{c}\right)+\left[(1-\alpha) u_{2}\left(x_{2+1}^{c}\right)\left(a_{t}+\rho_{t+1}\left(1-a_{t}\right)\right)+\alpha u_{2}\left(x_{2 t+1}^{c *}\right)\right] \frac{p_{y t}}{p_{x t+1}}+p_{y t} \mu_{2} \lambda=0 \\
\alpha u_{2}\left(x_{2 t+1}^{c *}\right) \frac{1-\rho_{t+1}}{p_{x t+1}}-\mu_{2} \rho_{t+1}=0
\end{gathered}
$$

where $\mu_{2}$ is the Lagrangian multiplier associated with creditor's liquidity constraint. If the liquidity constraint is not binding, then by (13) we have $\rho_{t+1}=1$ and $x_{2 t+1}^{c}=x_{2 t+1}^{c *}$. Combining the two FOCs, we get,

$$
-\frac{u_{1}\left(y_{1 t}^{c}\right)}{p_{y t}}+\left(a_{t}+\rho_{t+1}\left(1-a_{t}\right)\right)\left((1-\alpha) \frac{u_{2}\left(x_{2 t+1}^{c}\right)}{p_{x t+1}}+\alpha \frac{1}{\rho_{t+1}} \frac{u_{2}\left(x_{2 t+1}^{c *}\right)}{p_{x t+1}}\right)=0
$$




\subsection{Equilibrium}

A Nash equilibrium is defined as (i) price-taking debtors and creditors maximize expected lifetime welfare; (ii) all markets clear; and (iii) the believed measure of debtors arriving at the central island in the morning is equal to the actual measure of debtors arriving in the morning.

The goods market clearing conditions are

$$
\begin{aligned}
y & =y_{1 t}^{c}+\lambda k_{t}+(1-\lambda) k_{t}^{*}, \\
x+\lambda f\left(k_{t-1}\right)+(1-\lambda) F\left(k_{t-1}^{*}\right) & =\lambda\left(x_{1 t}^{d}+x_{2 t}^{d}\right)+(1-\lambda)\left(x_{1 t}^{d *}+x_{2 t}^{d *}\right)+(1-\alpha) x_{2 t}^{c}+\alpha x_{2 t}^{c *} .
\end{aligned}
$$

In additon, the market for good $x$ in the morning need to satisfy

$$
x+\lambda f\left(k_{t-1}\right) \geq \lambda x_{1 t}^{d}+(1-\lambda) x_{1 t}^{d *}+(1-\alpha) x_{2 t}^{c} .
$$

The inequality does not have to bind because good $x$ can be sold to the old debtors and afternoon-leaving creditors in the afternoon.

The money market clearing condition is

$$
\lambda m_{t}+(1-\lambda) m_{t}^{*}=m_{0}
$$

The loan market clearing condition is

$$
l_{t}=\lambda h_{t}+(1-\lambda) h_{t}^{*}
$$


The equilibrium proportion of debts that is repaid early is

$$
a_{t}=\frac{\lambda h_{t}}{\lambda h_{t}+(1-\lambda) h_{t}^{*}} .
$$

The loan resale market clearing condition is

$$
\lambda b_{t}+\alpha q_{t}=(1-\alpha)\left(1-a_{t-1}\right) l_{t-1} .
$$

The first-order conditions and the market clearing conditions pin down the equilibrium amount of consumption goods for both agents, the relative prices of goods, the equilibrium ratio of morning producers, and the equilibrium price of loans in the resale market. Proposition 1 shows that in the equilibrium, there will be a fraction of, but not all, debtors choosing to be morning producers. The resale price of loan on the central island is always less than 1 , that is, the liquidity constraints are always binding in the resale market.

Proposition 1 There exists a mixed strategy Nash equilibrium, $\lambda \in(0,1)$ and $\rho \in(0,1)$. Moreover, no pure-strategy Nash equilibrium exists.

Proof. Prove by contradiction. Suppose $\lambda=1$, which implies that all debtors are early producers. All IOUs are redeemed in the morning. There is no demand in the IOU resale market, which implies in unbinding liquidity constraints for morning producers and results in $\rho=1$. The morning producers will not gain at all from the resale market. As the return on the afternoon good strictly dominates that on the morning good, a debtor would have become an afternoon producer if $\rho=1$. Thus, we reach a contradiction.

Suppose alternatively that all debtors are afternoon producers; that is, $\lambda=0$. Then 
there is no supply of liquidity in the IOU resale market, which drives the discount rate $\rho$ to

0. One debtor would choose to be a morning producer to make infinite profit in the resale market. Again, a contradition.

That $\lambda$ is strictly between 0 and 1 implies that a debtor is indifferent to the technologies given the equilibrium $\lambda$. That is, a debtor cannot benefit from technology arbitrage in equilibrium.

$$
v\left(x_{1 t}^{d}, x_{2 t+1}^{d}\right)=v\left(x_{1 t}^{d *}, x_{2 t+1}^{d *}\right)
$$

The implication of proposition 1 is that there exists a nondegenerate equilibrium distribution of settlements. In this equilibrium, the debtor is indifferent between morning and afternoon production/settlement. Intuitively, debtors follow a mixed strategy in order to satisfy the nonarbitrage condition. Once at the settlement site, the morning producers can find creditors leaving early and offer payment at less than par for the IOUs. Because there is no default risk, the return to morning goods plus intra-period gains from the resale market equal the return on the afternoon goods.

In the following sections, we will focus on the stationary equilibrium, or the steady state. In the steady state, prices and allocations are invariant to time. So we will drop the time subscripts. ${ }^{6}$

\footnotetext{
${ }^{6}$ The uniqueness of the steady state is not guaranteed. But the uniquess exists in some classes of utility functions and production functions. For example, log linear utility function and Cobb-Douglas production functions.
} 


\section{Planner's allocation}

We now turn to the discussion of the unconstrained first-best allocation, or a planner's allocation. We assume that the planner selects one technology for each individual debtor. Thus, in the planner's allocation, $\lambda$ is the measure of debtors that the planner chooses to be

morning producers. In this section, we assume old creditor's consumption demand is not tied to their departure from the central island. It is the same assumption as made in Freeman (1996). Later, we consider a different consumption pattern in Section 6.

Following Mills (2004), we set up a social planner's problem as follows.

$$
\begin{aligned}
& \max _{y_{1}^{c}, x_{2}^{c}, x_{2}^{c *}, x_{1}^{d}, x_{2}^{d}, x_{1}^{d *}, x_{2}^{d *}, k, k^{*}, \lambda} \beta\left[\begin{array}{c}
\lambda v\left(x_{1}^{d}, x_{2}^{d}\right)+ \\
(1-\lambda) v\left(x_{1}^{d *}, x_{2}^{d *}\right)
\end{array}\right]+(1-\beta)\left[\begin{array}{c}
\alpha u\left(y_{1}^{c}, x_{2}^{c *}\right)+ \\
(1-\alpha) u\left(y_{1}^{c}, x_{2}^{c}\right)
\end{array}\right] \\
& \text { s.t. } \quad x+\lambda f(k)+(1-\lambda) F\left(k^{*}\right)=(1-\alpha) x_{2}^{c}+\alpha x_{2}^{c *}+\lambda\left(x_{1}^{d}+x_{2}^{d}\right)+(1-\lambda)\left(x_{1}^{d *}+x_{2}^{d *}\right) \\
& \quad y=y_{1}^{c}+\lambda k+(1-\lambda) k^{*} \\
& \quad 0 \leq \lambda \leq 1
\end{aligned}
$$

where $\beta$ is the weight of debtors in the planner's welfare function. The first two constraints are the resource constraints for goods $x$ and $y$, respectively.

The solution to the planner's problem, denoted by the "hat" on the variables, satisfies the following first-order conditions that describe the consumptions for each type of agents 
in both periods:

$$
\begin{aligned}
v_{1}\left(\hat{x}_{1}^{d *}\right) & =v_{2}\left(\hat{x}_{2}^{d *}\right), \\
v_{2}\left(\hat{x}_{2}^{d *}\right) & =\frac{1-\beta}{\beta} u_{2}\left(\hat{x}_{2}^{c *}\right), \\
u_{1}\left(\hat{y}_{1}^{c}\right) & =u_{2}\left(\hat{x}_{2}^{c *}\right) F^{\prime}\left(\hat{k}^{*}\right), \\
\hat{x}_{2}^{c} & =\hat{x}_{2}^{c *} .
\end{aligned}
$$

Because the old creditors are indifferent to when they consume in the second period of their life and because afternoon production dominates morning production, the planner's allocation consists only of afternoon production; that is, $\hat{k}=0$ and $\hat{\lambda}=0$. The planner provides full risk sharing to creditors. A morning-leaving creditor's consumption is not affected by his departure from the central island because the planner provides the consumption good during the appropriate subperiod. A planner can always redistribute goods to achieve the desired wealth distribution that satisfies equation (17).

Compare the decentralized economy and the planner's allocation. It is easy to see that the decentralized economy does not achieve the planner's allocation. Two reasons account for this. First, in a decentralized economy, IOUs must be discounted to attract some of the debtors to arrive early. While the resale market provides liquidity for morning-leaving creditors, it shifts production to a low-return technology, reducing total consumption and incomplete risk sharing among creditors. In a planner's economy, the planner maximizes total production, distributing goods to the creditors at the appropriate consumption time and providing full risk sharing. Second, the planner achieves the optimal allocation by costlessly redistributing goods to satisfy equation (17). 


\section{Government policies}

So, the equilibrium outcomes in the decentralized economy are not the same as the planner's allocation. Is there a policy in the decentralized economy that will implement the efficient allocation?

There exists a central bank on the central island. The central bank provides a discount window service that supplies unlimited loans at the interest rate of $1+r$ in the morning of each period. Only intraday loans are offered; loans made in the morning must be repaid in the afternoon. We assume that the central bank keeps the end-of-period stock of fiat money constant for all periods. ${ }^{7}$ In this economy, the afternoon-leaving creditors and morning producers trade between the central bank and morning-leaving creditors as "commercial banks." The competitive market will result in a non-arbitrage condition in which $\rho=\frac{1}{1+r}$.

In addition to the central bank, a government operates a lump-sum tax and transfer process. We use the vector $\left(T_{d}, T_{d^{*}}, T_{c}, T_{c^{*}}\right)$ to denote the tax-transfer scheme, where $T_{d}, T_{d^{*}}, T_{c}, T_{c^{*}}$ are the net life-time transfers to the morning-producer, afternoon-producer, morning-leaving creditor, and afternoon-leaving creditors, respectively. ${ }^{8}$ The government runs a balanced budget in each period. We look for an optimal discount rate on the resale loan that can maximize the social welfare in the decentralized economy.

Proposition 2 In the decentralized economy, the optimal intraday rate is zero.

Proof. Let $\rho=1, T_{d^{*}}>T_{d}$, and $T_{c}=T_{c^{*}}$. Because there is no profit in the resale market

\footnotetext{
${ }^{7}$ Central bank loans can be considered outside money. The constant stock of outside money referred to here then is "unbacked" outside money. Any outside money created through the discount window is "backed" outside money, where backing refers to the loan itself. For example, suppose the central bank loan is repaid with goods. For this case, we assume that the central bank can sell the goods on the debtor islands. In this way, central bank loans are equal to zero at the end of each period.

${ }^{8}$ The lump-sum tax and transfer scheme is implicit in [7] and other works (see [16]). The balanced-budget constraint is $(1-\lambda) T_{d}+(1-\alpha) T_{c}+\lambda T_{d^{*}}+\alpha T_{c^{*}}=(1-\rho)[(1-\alpha)(1-\lambda) l-\lambda b-\alpha q]$.
} 
and afternoon producers receive transfers, debtors will produce the afternoon good only. The debtor's first-order condition (7) is reduced to (26). Because there is no profit in the resale market and all creditors receive the same transfers/tax, creditors receive same consumption. Thus, we have $x_{2}^{c}=x_{2}^{c *}$ and the creditor's first-order condition (14) is reduced to (18). Lastly, the value of $T_{d^{*}}$ and $T_{c^{*}}$ can be chosen in such a way that the marginal utility between two types of agents satisfies (16).

As in Freeman, Proposition 2 indicates that morning-leaving creditors do not care about when they obtain consumption goods during the day; early departure imposes a pure liquidity problem. The bank can counteract this friction by injecting money temporarily into the economy.

\section{Diamond-Dybvig type creditor}

In this section, we consider an economy in which the locational shock to old creditors is perfectly correlated with a consumption shock. In other words, creditors that leave the central island in the morning must also consume in the morning. As such, afternoon goods cannot substitute for morning goods from the perspective of old morning-leaving creditors. Note that endowments are available for morning consumption and thus are perfect substitutes for the morning good.

In our view, we are incorporating a friction in which resource commitment corresponds to settlement time. Martin and McAndrews [14] assert, “... banks face a variety of deadlines to make payments during the day." (p.17) By assuming that morning and afternoon goods are imperfect substitutes, we are treating one possible deadline as consistent with the timing 
of consumption. Insofar as the timing of consumption matters, production may also be affected. There is an opportunity cost that is present as the planner shifts production from the afternoon to the morning. Let "Freeman-type" creditors refer to those creditors who treat morning goods and afternoon as perfect substitutes, such as in the previous model economy. Compared with Freeman-types, creditors asymmetrically distinguish between morning goods (apples) and afternoon goods (oranges) in this modified model economy. For afternoon departees, apples and oranges are perfect substitutes. For the morning leavers, oranges are useless. ${ }^{9}$ Thus, by shifting production to morning apples, we get fewer total goods for the afternoon leavers for the sake of the morning leavers.

By modelling the possible link between payment receipts and consumption purchases, we treat the possibility that there is a one-for-one link between when the creditor needs to be paid and a consumption opportunity. Formally, we can study the implications of a model in which the creditor, whose settlement takes place in the morning, is also seeking the consumption good at exactly the same time as settlement occurs. We refer to these creditors as Diamond-Dybvig [6] creditors. $^{10}$

\subsection{Planner's allocation}

The planner faces an additional resource constraint. Because the morning good is different from the afternoon good, there must be enough mornign good to meet the consumption

\footnotetext{
${ }^{9}$ See Martin [13] for a Diamond-Dybvig economy with commodity money. Because of the resources associated with the commodity money, the loan interest rate should be positive in this economy.

${ }^{10}$ In their paper, Diamond-Dybvig consumers are subject only a consumption shock. We realize that we take some liberty since our consumers are subject to joint consumption and location shocks.
} 
needs by morning-leaving creditors. Formally,

$$
x+\lambda f(k) \geq(1-\alpha) x_{2}^{c}
$$

Three cases are associated with this constraint.

Case 1: The resource constraint (20) is nonbinding, implying that $(1-\alpha) \hat{x}_{2}^{c}<x$ and $\hat{\lambda}=0$. Then the planner's solution is identical to allocation with Freemn-type creditors.

Case 2: The resource constraint (20) is binding, and the planner's solution requires $\hat{\lambda}=0$ and $(1-\alpha) \hat{x}_{2}^{c}=x$. In this case, the planner still invests all resources in the production of afternoon goods. He rations the endowments of the young debtors among the morningleaving creditors. The planner's solution is described by equations (16) - (18) and the resource constraint. Because of the binding resource constraint and by concavity of the utility function, we have

$$
\hat{x}_{2}^{c}<\hat{x}_{2}^{c *} .
$$

Case 3: The resource constraint (20) is binding, and the planner's solution requires $\hat{\lambda}>0$ and $(1-\alpha) \hat{x}_{2}^{c}>x$. The planner invests some resources in producing the morning goods, and allocates the endowments of the young debtors and morning goods to the morning-leaving 
creditors. The first-order conditions are

$$
\begin{aligned}
\hat{x}_{1}^{d} & =\hat{x}_{1}^{d *}, \\
\hat{x}_{2}^{d} & =\hat{x}_{2}^{d *}, \\
u_{1}\left(\hat{y}_{1}^{c}\right) & =u_{2}\left(\hat{x}_{2}^{c}\right) f^{\prime}(\hat{k}), \\
u_{2}\left(\hat{x}_{2}^{c}\right) f(\hat{k})-u_{1}\left(\hat{y}_{1}^{c}\right) \hat{k} & =u_{2}\left(x_{2}^{c *}\right) F\left(\hat{k}^{*}\right)-u_{1}\left(\hat{y}_{1}^{c}\right) \hat{k}^{*} .
\end{aligned}
$$

and equations (16) - (18) . (21) still hold in this case. Equation (25) describes the tradeoff embedded in the production allocation. The left-hand side of (25) is the marginal value from an inputs applied to morning production while the right-hand side is the marginal value obtained from inputs applied to afternoon production. The optimal $\lambda$ equates the net marginal gain of these two types of production. Also note that equations $(16),(22)$, and (23), imply the following equation for a morning producer's intertemporal consumption decision:

$$
v_{1}\left(\hat{x}_{1}^{d}\right)=v_{2}\left(\hat{x}_{2}^{d}\right)
$$

The return on morning good production is lower than that on the afternoon good. Because the endowments of the young debtors and morning goods are perfect substitutes to the morning-leaving creditors, the planner first applies the endowment to satisfy the consumption by morning-leaving creditors. Case 1 verifies that if the amount of endowment is large enough to satisfy old morning creditors' demand, then the planner's allocation achieves full risk sharing. In contrast, if the endowment is not large enough, the planner finds the efficient trade-off between the morning-leaving creditor's intertemporal marginal rate of intertempo- 
ral substitution (IMRS) and the marginal product (MP) of the morning production. If, when evaluated at the endowment quantity, the IMRS is higher than MP, the planner will simply ration the endowment of the young to the morning-leaving creditors (Case 2). In contrast, if the IMRS is less than the MP when evaluated at the endowment quantity, the planner's allocation will consist of both morning and afternoon production. In the efficient allocation, morning good production is set to equate IMRS and MP (Case 3). Both Cases 2 and 3 are characterized by the planner's allocation achieving partial risk sharing in the sense that the morning-leaving creditors consume less than afternoon-leaving ones. In those two cases, the planner compensates the creditor by increasing their consumption when young. Investment declines. Thus, compared with Case 1, it follows immediately that there is less afternoon production and less total production in Cases 2 and 3.

\subsection{Equilibrium in the decentralized economy revisited}

With $\lambda>0$, it is easy to see that the equilibrium in the decentralized economy does not achieve the planner's allocation for Cases 1 and 2. Though less obvious, the Case 3 planner's allocation is not achieved in the decentralized economy. Note that the planner's allocation calls for $v_{1}\left(\hat{x}_{1}^{d}\right)=v_{2}\left(\hat{x}_{2}^{d}\right)$; that is, morning producer's IMRS is equal to one. However, in the decentralized economy with $0<\rho<1$, the morning producer's optimal choice requires $v_{1}\left(x_{1}^{d}\right)>v_{2}\left(x_{2}^{d}\right)$ by the first-order condition. In other words, morning producer's IMRS is less than one. 


\subsection{Government policies}

We discuss optimal central bank policies in three cases in the economy with Diamond-Dybvig type of creditors, corresponding to the three separate planner's solutions.

Case 1: $(1-\alpha) \hat{x}_{2}^{c}<x$

The planner's solution has an unbinding resource constraint in the morning. The solution is characterized by the same system of equations as in the economy with Freeman type of creditors. The optimal discount rate is $\rho=1$, and the policy in the decentralized economy can implement the planner's allocation.

Case 2: $(1-\alpha) \hat{x}_{2}^{c}=x$ and $\hat{\lambda}=0$.

Suppose the discount rate policy $\rho=1$. The creditor's first-order condition is

$$
u_{1}\left(y_{1}^{c}\right)=F^{\prime}\left(k^{*}\right)\left[(1-\alpha) u_{2}\left(x_{2}^{c}\right)+\alpha u_{2}\left(x_{2}^{c *}\right)\right] .
$$

If $x_{2}^{c}=x_{2}^{c *}$, the creditor's FOC is identical to equation (18). But $x_{2}^{c}=x_{2}^{c *}$ contradicts the planner's allocation with $\hat{x}_{2}^{c}<\hat{x}_{2}^{c *}$.

There exists a positive intraday interest rate policy that does implement the planner's allocation. To achieve $\lambda=0$ in the decentralized economy, $T_{d}$ can be set sufficiently low to induce all debtors to be afternoon producers. The afternoon producer's decision is independent of $\rho$. Let $\rho=\frac{u_{2}\left(\hat{x}_{2}^{c *}\right)}{u_{2}\left(\hat{x}_{2}^{c}\right)}=\frac{u_{2}\left(\hat{x}_{2}^{c *}\right)}{u_{2}\left(\frac{x}{1-\alpha}\right)}$, so that the creditor's first-order condition in the decentralized economy becomes

$$
u_{1}\left(y_{1}^{c}\right)=F^{\prime}\left(k^{*}\right)\left[(1-\alpha) \frac{u_{2}\left(\hat{x}_{2}^{c *}\right)}{u_{2}\left(\hat{x}_{2}^{c}\right)} u_{2}\left(x_{2}^{c}\right)+\alpha u_{2}\left(x_{2}^{c *}\right)\right] .
$$


It is easy to see that $\left(\hat{y}_{1}^{c}, \hat{k}^{*}, \hat{x}_{2}^{c *}, \hat{x}_{2}^{c}\right)$ is the solution to $(27)$, which is identical to (18). Hence, with $\rho=\frac{u_{2}\left(\hat{x}_{2}^{c *}\right)}{u_{2}\left(\hat{x}_{2}^{c}\right)}$, the quantity produced in the decentralized economy is identical the planner's production level.

Aggregate transfers are represented by $(1-\alpha) T_{c}+\alpha T_{c^{*}}+T_{d^{*}}=(1-\rho)(1-\alpha) l$. Note that the aggregate transfers are funded by profits made from the discount window loans. The tax-transfer scheme can be designed to achieve the desirable consumption allocation among all agents. ("consumption allocation" may be too general. We mean the desirable welfare weights, right?)

Case 3: $(1-\alpha) \hat{x}_{2}^{c}>x$ and $\hat{\lambda}>0$.

In this case, there does not exist an intraday interest rate policy that can implement the planner's allocation. To see this, note that $\rho$ appears both in the morning producer's and the creditor's intertemporal consumption decisions, [see equations (4) and (14)]. Equation (4) is not identical to equation (26) in the planner's first-order condition, unless $\rho$ is set to be 1 . With $\rho=1$, equation (14) in steady state becomes

$$
u_{1}\left(y_{1}^{c}\right)=(1-\alpha) u_{2}\left(x_{2}^{c}\right) f^{\prime}(k)+\alpha u_{2}\left(x_{2}^{c *}\right) F^{\prime}\left(k^{*}\right),
$$

which is not identical to the intertemporal consumption decisions in the planner's solution (equations (18) and (24)) unless we have $x_{2}^{c}=x_{2}^{c *}$. But it contradicts the fact that $\hat{x}_{2}^{c}<\hat{x}_{2}^{c *}$ in the planner's solution.

We summarize the discussion to the following proposition.

Proposition 3 In the economy with Diamond-Dybvig type creditors, (i) if the planner's resource constraint in the morning is nonbinding (Case 1$)$, then setting $\rho=1$ (or $r=0$ ) 
implements the planner's allocation; (ii) if the planner's resource constraint in the morning is binding and the resource equals the consumption by morning-leaving creditors (Case 2), then setting $\rho=\frac{u_{2}\left(\hat{x}_{2}^{c *}\right)}{u_{2}\left(\hat{x}_{2}^{c}\right)}$ (or $r=\frac{u_{2}\left(\hat{x}_{2}^{c}\right)}{u_{2}\left(\hat{x}_{2}^{* *}\right)}-1$ ) implements the planner's allocation; (iii) if endowments are strictly less than consumption by morning-leaving creditors (Case 3), then no intraday rate can implement the planner's allocation.

The intuition behind proposition 3 is as follows. In the planner's allocation, the morningleaving (afternoon-leaving) creditor's IMRS is equal to the marginal product of morning (afternoon) production. Compared with the afternoon-leaving creditors, the morning-leavers are treated less favorably (at most equally) because morning goods are more costly. The intraday rate in the decentralized economy, which measures the price of morning consumption relative to the afternoon consumption, should be positive to match the planner's consumption allocation among the creditors. However, this positive intraday rate also measures the IMRS of the morning producers, who trade high return on production for profits in the resale market. From the planner's point of view, debtor's IMRS should be one because the consumption needs of the debtors (either morning or afternoon producers) are time-insensitive within a period. In other words, to match the planner's consumption allocation for the morning producers, we need to set the intraday rate at 0 . So in general, the one intraday rate cannot achieve the efficient IMRS of the morning producers (which requires $r=0$ ) and the creditors (which requires $r \geq 0$ ).

The exception occurs in cases 1 and 2. In Case 1, the endowments of the young debtors are large enough to satisfy the consumption demand of the morning-leaving creditors. Morning consumption does not come at the cost of afternoon consumption. The timing issue becomes 
a pure liquidity problem as in the economy with Freeman-type creditors, and providing free liquidity can solve the problem. In Case 2, endowments are not large enough, but the morning-leaving creditor's IMRS, evaluated at the endowment point, is still large relative to marginal product in the morning production. By imposing a heavy tax on morning producers, we can induce all debtors to be afternoon producers. The intraday rate, therefore, can be used exclusively to target the intertemporal efficiency condition of the creditors.

Alternatively, let us expand on this intuition by focusing attention on the planner's production scheme. Three variables fully characterize the production scheme in the planner's allocation: (i) the fraction of debtors who are engaged in morning good production $(\lambda)$, (ii) the quantity of capital invested in morning good production $(k)$, and (iii) the quantity of capital put in afternoon good production $\left(k^{*}\right)$. In Case 3, all three variables are nontrivial and must be matched for the decentralized economy to implement the planner's allocation. The government has two policy tools: the intraday rate and tax-transfer scheme. It follows that the policy tools are outnumbered by variables that fully characterize the planner's production scheme. So we cannot achieve the planner's allocation in general. ${ }^{11}$ Again, cases 1 and 2 are special. In these two cases, there is no morning production in the planner's production scheme. By setting taxes on morning producers high enough, we encourage all debtors to choose afternoon production. With $\lambda=0$, the choice of $k$ is trivial. Hence, we have only one variable, $k^{*}$, in the planner's production scheme that must be matched. By setting the positive intraday interest rate properly, we can adjust the creditors' IMRS such that $k^{*}=\hat{k}^{*}$.

A secondary and subtle reason accounts for why central bank policies cannot implement

\footnotetext{
${ }^{11}$ See appendix for the discussion of a time-contingent IOU contract.
} 
the planner's allocation in Case 3. Hidden action plays an important role in terms of the relative price of capital. Debtors' production choices are not observable ex ante. As creditors cannot distinguish between morning and afternoon producers, they cannot sell capital at different prices to debtors who invest in different production. Thus, there is one price of capital despite two types of production, and the choices of $k$, and $k^{*}$ are both distorted. ${ }^{12}$

In the economy with Freeman-type creditors, the tax-transfer scheme merely redistributes consumption among all agents to achieve the desirable welfare weights in the planner allocation. In the economy with Diamond-Dybvig creditors, the tax-transfer scheme also affects the capital gains in the IOU resale market. In case 2, for example, the optimal intraday rate is positive. It follows that capital gains are earned by purchasing IOUs in the morning and settling them in the afternoon. With no tax-transfer scheme, some debtors would choose to be morning producers if the intraday rate is high enough. To implement the efficient allocation with a degenerate distribution of settlements, the government must tax morning producers. Here, the tax cancels capital gains and only afternoon production takes place. In case 3, the tax-transfer scheme adjusts the size of the capital gains. The planner's allocation cannot be achieved, but the tax-transfer scheme, together with a positive intraday rate, is second best.

Case 2 follows a theme in the literature on the Friedman rule. In separate papers, Martin and McAndrews [14] and Bhattacharya, Haslag and Martin [4] demonstrate that in an economy with production externalities, the optimal policy will deviate from the Friedman rule. ${ }^{13}$ In Bhattacharya, et al., the relocation shock is distinguished between early movers

\footnotetext{
${ }^{12}$ See appendix for the discussion of an economy with no hidden action.

${ }^{13}$ See also [15]. Our paper also overlaps substantially with [12] in addressing settlement risk with monetary policy tools. In [12], paying the market rate of interest on reserves is analogous to the Friedman rule.
} 
and late movers. Early movers impose a cost on society in the form of reduced production. Intraday interest rates and overnight rates play two distinct roles. The overnight rate affects output, while the intraday rate affects the distribution of resources between money holders and non-money holders. It is optimal to deviate from the Friedman rule because a positive overnight rate reduces the incentive to overuse money and encourages risk sharing. Here, the externality is embodied in the production of morning goods versus afternoon goods. For afternoon leavers, there is a single consumption good and shifting production to the morning results in a loss of the total quantity of goods. With a positive intraday interest rate, morning creditors/consumers realize less consumption to compensate for the lower marginal product that comes with shifting production from afternoon to morning.

Some related literature favoring positive intraday rate emphasizes moral hazard problem. Chapman and Martin [5] develop a model in Freeman's [8] framework to show that in an economy with moral hazard problem, the optimal intraday rate is positive if default occurs. ${ }^{14}$ With a positive intraday rate, creditors are encouraged to use resources to monitor the quality of the loans thus reducing the default risk. Our model provides an alternative explanation that relies on the opportunity cost of settling payments early.

The literature on the endogenous distribution of settlements is thin. Bech and Garrett [3] apply a partial equilibrium approach to examine the distribution of settlements. Banks receive payment requests and strategically choose when to release the funds to settle the payment request. In a collateralized credit regime when liquidity is costly, there arises a prisoners' dilemma that yields a degenerate distribution of settlements that occur in the afternoon. This equilibrium is socially inefficient. In a priced credit regime, there can arise

\footnotetext{
${ }^{14}$ See also [14] for a survey of literature on intraday money market.
} 
a stag hunt game in which either all banks settle all in the morning or all in the afternoon. Delay is socially optimal when the payment flows are skewed towards the afternoon. By proposing a general equilibrium framework, we can address the role that the intraday rate policy has on the equilibrium distribution of settlements.

\subsection{A numeric example (Diamond-Dybvig type of creditor)}

In this example, utility functions are: $v\left(x_{1 t}^{d}, x_{2 t+1}^{d}\right)=\ln x_{1 t}^{d}+\ln x_{2 t+1}^{d}$, and $u\left(y_{1 t}^{c}, x_{2+1}^{c}\right)=$ $\ln y_{1 t}^{c}+\ln x_{2 t+1}^{c}$. Creditors and debtors are equally weighted. That is, $\beta=0.5$.

Endowments: $x=0.2, y=1$.

Production functions: $f(k)=k^{1 / 3}, F(k)=2^{2 / 3} k^{1 / 3}$.

Figure 1 shows the weighted average expected utility of the debtors and creditors (social welfare) in a decentralized economy, a planner's economy, and a decentralized economy with central bank policies. The blue line represents the utility in a decentralized economy, the black line indicates the utility in a planner's economy, and the red line indicates the utility under the optimal central bank policies when the planner's allocation is not achievable. We also plot the weighted average utility under the zero-intraday-rate policy and the tax-transfer scheme when zero intraday rate is not optimal. It is represented by the green line.

If the fraction of late-leaving creditors, $\alpha$, is greater than fifty percent, then the first-stage resource constraint is not binding in the planner's allocation. That is, $x>(1-\alpha) \hat{x}_{2}^{c}$. In the decentralized economy, the central bank will want to choose $\rho=1$ to implement the planner's allocation. This is why the central bank policy welfare line coincides with the planner's welfare line for $\alpha \geq 0.5$. 
Figure 1 further shows what happens when $0.36 \leq \alpha<0.50$. Here, the first-stage resource constraint is binding in the planner's problem so that $x=(1-\alpha) \hat{x}_{2}^{c}$. The optimal discount rate that the central bank sets is $\rho=\frac{u_{2}\left(\hat{x}_{2}^{c *}\right)}{u_{2}\left(\hat{x}_{2}^{c}\right)}<1$. This central bank policy implements the planner's allocation. The central bank policy welfare line also coincides with the planner's welfare line for $0.36 \leq \alpha<0.50$. For $\alpha<0.36$, no discount rate can implement the planner's allocation, and the welfare is strictly less than that under the planner's allocation. However, the allocation is better than the decentralized economy without the central bank policies. If the central bank insists on providing zero intraday rate, social welfare is stricly worse off. In the figure, we observe that the green line is below the black line and the red line. It is even worse than that under no policy intervention if $\alpha$ is sufficiently small.

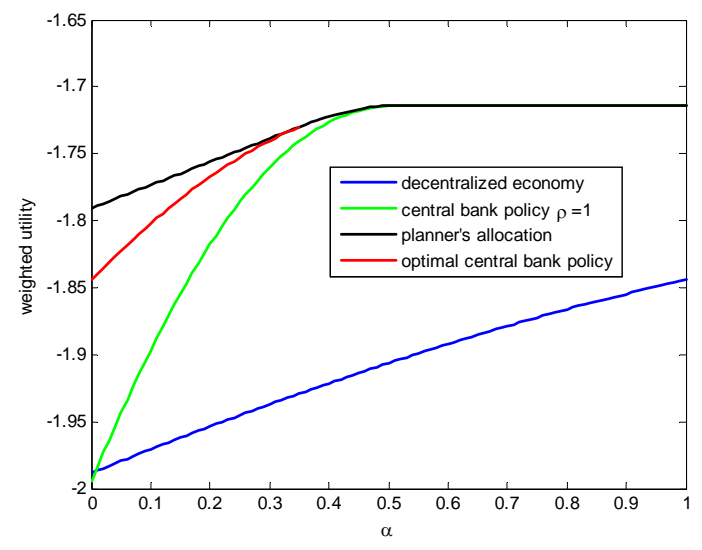

Figure1: An example of the social welfare under the planner's allocation, decentralized economy, and the decentralized economy with the central bank policies.

Table 1 lists the details of the decentralized economy, planner's allocation, and the decentralized economy with central bank policies for $\alpha=0$. The consumptions and utilities of the debtors and creditors, and the weighted average aggregate utility, $\omega$, are as follows: 
Table 1: An example of the allocation in a decentralized economy, planner's allocation, and central bank policies $(\alpha=0)$

\begin{tabular}{llllllll}
\hline \hline & $v$ & $x_{1}^{d}$ & $x_{2}^{d}$ & $k$ & $x_{1}^{d *}$ & $x_{2}^{d *}$ & $k^{*}$ \\
Decentralized economy & -2.0999 & 0.2000 & 0.6124 & 0.3750 & 0.2000 & 0.6124 & 0.7500 \\
Planner's allocation & -1.6372 & 0.4411 & 0.4411 & 0.5411 & 0.4411 & 0.4411 & 0.5411 \\
Optimal policies & -1.3863 & 0.3162 & 0.7906 & 0.2500 & 0.5000 & 0.5000 & 0.5000 \\
0-intraday rate & -0.9751 & 0.6141 & 0.6141 & 0.3772 & 0.6141 & 0.6141 & 0.7543 \\
\hline & $u$ & $y_{1}^{c}$ & $x_{2}^{c}$ & $x_{2}^{c *}$ & $\lambda$ & $\rho$ & $\omega$ \\
Decentralized economy & -1.8767 & 0.5000 & 0.3062 & 0.6124 & 0.6667 & 0.5000 & -1.9883 \\
Planner's allocation & -1.9442 & 0.4589 & 0.3119 & 0.4411 & 0.1521 & $N . A$. & -1.7907 \\
Central bank policies & -2.3026 & 0.5000 & 0.2000 & 0.5000 & 0.0000 & 0.4000 & -1.8444 \\
0-intrady rate & -3.0133 & 0.2457 & 0.2000 & 0.6141 & 0.0000 & 1 & -1.9942 \\
\hline \hline
\end{tabular}

When $\alpha=0$, the zero-intrady rate is not optimal in the decentralized economy with central bank policies. As Table 1 shows, the welfare under zero intraday rate is even lower than under no policy intervention. The optimal central bank policy requires positive intraday rate and a tax-transfer policy $\left(T_{d} / p_{x}=0.0479, T_{d^{*}} / p_{x}=0.1094, T_{c} / p_{x}=0.0000, T_{c^{*}} / p_{x}=\right.$ $-0.1094)$. Note that given the discount rate $\rho=0.4000$ and the tax-transfer scheme, no debtors will choose the first-stage production. The chance of being treated unfavorably when old adversely affects the creditor's consumption decision when young. The young creditors choose to consume more and sell less capital, which reduce the total production and thus the consumption of other agents.

\section{Summary and conclusion}

In this paper, we derive three main results. First, we develop a model economy in which the timing of payment settlement is endogenously determined. Thus, there is an equilibrium distribution of settlements within a day.

Second, we use this model economy to study optimal intraday interest rate policy. In 
the first version of the model, we follow Freeman's approach, treating morning consumption and afternoon as perfect substitutes. Under this assumption, we show that a zero-intraday interest rate policy is optimal. In addition, the zero-intraday-rate policy achieves perfect risk sharing for consumers. Because the morning and afternoon goods are perfect substitutes, allocating all resources into high-return afternoon production maximizes aggregate consumption. Lastly, the equilibrium distribution of settlements is degenerate with all payments settled in the afternoon. The empirical evidence indicates that a preponderance of settlements occur in the afternoon.

Third, we consider a version of the model economy in which morning goods and afternoon goods are not perfect substitutes. In this version, there is a perfect correlation between a locational shock and the consumption-timing shock. The critical feature is whether production needs to be shifted to the morning so that morning consumers can eat. In two cases, the endowments are insufficient to obtain perfect risk sharing. In both cases, a positive intraday interest rate is necessary; the intraday rate is the relative price between afternoon and morning consumption. In one case, the positive intraday rate is part of a policy package that implements the planner's allocation. In this case, the morning consumer's intertemporal marginal rate of substitution is greater than the rate at which capital is transformed into morning goods when evaluated at the endowment quantity. The efficient allocation is characterized by afternoon production only with the morning consumer realizing lower consumption than the afternoon consumer. In the other case, when evaluated at the endowment quantity, the morning consumer's intertemporal marginal rate of substitution is less than the rate at which capital is transformed into the morning good. Therefore, some production is shifted from the afternoon to the morning. The morning consumer realizes lower consump- 
tion than the afternoon consumer. And the reduction in the afternoon production means fewer goods are available for all other agents. For this last case, the intraday rate policy is positive. There is no intraday rate policy that can implement the efficient allocation. Because central bank policy cannot implement the planner's allocation, a third policy tool must be considered.

Overall, our findings indicate that the nature of settlements and the timing of consumption tied to settlement are potentially important factors when examining optimal intraday interest rate policy. It seems quite plausible that creditors will have time-sensitive consumption opportunities present themselves. When the settlement timing is endogenously determined, we derive conditions under which welfare is harmed by adopting a zero intraday interest rate policy. We leave the question about the appropriate policy structure for future research. 


\section{References}

[1] P. Angelini, An analysis of competitive externalities in gross settlement systems, Journal of Banking and Finance 22 (1998) 1-18.

[2] O. Armantier, J. Arnold, J. McAndrews, Changes in the Timing Distribution of Fedwire Funds Transfers, Federal Reserve Bank of New York Economic Policy Review 14 (2008), 83-112.

[3] M. Bech, R. Garratt, The intraday liquidity management game, Journal of Economic Theory 109 (2003) 198-219.

[4] J. Bhattacharya, J. H. Haslag, A. Martin, Why does overnight liquidity cost more than intraday liquidity, Journal of Economic Dynamics and Control 33 (2009) 1236-46.

[5] J. Chapman, A. Martin, Rediscounting under aggregate risk with moral hazard, Federal Reserve Bank of New York Staff Reports no. 296 (2007).

[6] D. Diamond, P. Dybvig, Bank runs, deposit insurance, and liquidity, Journal of Political Economy 91 (1983) 401-419

[7] S. Freeman, The payments system, liquidity, and rediscounting, American Economic Review 86 (1996) 1126-1138.

[8] S. Freeman, Rediscounting under aggregate risk, Journal of Monetary Economics 43 (1999) 197-216.

[9] S. Freeman, Payments and output, Review of Economic Dynamics 5 (2002) 602-17.

[10] E. Green, Money and debt in the structure of payments, Monetary and Economic Studies 215 (1997) 63-87.

[11] C. Gu, M. Guzman, J. H. Haslag, Production, hidden Action, and the payment system, University of Missouri working paper (2010).

[12] J. Lacker, Clearing, Settlement and monetary policy, Journal of Monetary Economics 40 (1997) 347-81.

[13] A. Martin, Reconciling Bagehot and the Fed's response to September 11, Journal of Money, Credit, and Banking 41 (2008), 397-415.

[14] A. Martin, J. McAndrews, Should there be intraday money markets. Federal Reserve Bank of New York Staff Reports no. 337 (2008).

[15] S. Millard, A. E. H. Speight, M. Willison, Why do central banks observe a distinction between intraday and overnight interest rate, manuscript (2006) Bank of England.

[16] D. C. Mills Jr., Mechanism design and the role of enforcement in Freeman's model of payments, Review of Economic Dynamics 7 (2004) 219-236. 


\section{Appendix}

\subsection{A contingent IOU contract}

Consider a contingent IOU contract. If redeemed in the morning, the debtor pays the face value (without loss of generality). Otherwise, the debtor pays $1+\gamma$ times the nominal value of the production loan. To simplify the presentation, we only consider the steady state equilibrium. First we show that the equilibrium discount rate and interest rate on the production loan satisfy $\rho(1+\gamma)=1$.

A creditor can choose $\gamma$ different from the equilibrium rate to attract morning or afternoon producers. Let $\gamma^{*}$ be the equilibrium interest rate of the production loan. If a creditor chooses to offer $\gamma>\gamma^{*}$, only morning producers will buy from him. If he chooses $\gamma<\gamma^{*}$ (and charge a small interest rate on the production loan made to the morning producers), he will attract only the afternoon producers. Thus, the fraction of the loan that will be repaid in the morning is

$$
a= \begin{cases}0, & \text { if } \gamma<\gamma^{*} \\ \frac{\lambda k}{\lambda k+(1-\lambda) k^{*}}, & \text { if } \gamma=\gamma^{*} \\ 1, & \text { otherwise. }\end{cases}
$$

Also note that if a creditor offers $\gamma<\gamma^{*}$, he will offer $\gamma \rightarrow \gamma^{*}$ to maximize his income when old.

Suppose the creditor offers market interest rate $\gamma^{*}$. He maximizes his expected life-time utility subject to the budget constraints contingent on the realization of his type and the 
liquidity constraint if he leaves in the afternoon.

$$
\begin{array}{cc}
\max _{q, y_{1}^{c}, x_{2}^{c}, x_{2}^{c *}} & (1-\alpha) u\left(y_{1}^{c}, x_{2}^{c}\right)+\alpha u\left(y_{1}^{c}, x_{2}^{c *}\right) \\
\text { s.t. } & {\left[\rho\left(1+\gamma^{*}\right)(1-a)+a\right] p_{y}\left(y-y_{1}^{c}\right)=p_{x} x_{2}^{c}} \\
{\left[\left(1+\gamma^{*}\right)(1-a)+a\right] p_{y}\left(y-y_{1}^{c}\right)+(1-\rho)\left(1+\gamma^{*}\right) q=p_{x} x_{2}^{c *}} \\
a p_{y}\left(y-y_{1}^{c}\right)-\rho\left(1+\gamma^{*}\right) q \geq 0
\end{array}
$$

Solving the maximization problem, we have

$$
-u_{1}\left(y_{1}^{c}\right)+\frac{p_{y}}{p_{x}}\left[a+\rho\left(1+\gamma^{*}\right)(1-a)\right]\left((1-\alpha) u_{2}\left(x_{2}^{c}\right)+\frac{1}{\rho} \alpha u_{2}\left(x_{2}^{c *}\right)\right)=0
$$

and

$$
x_{2}^{c}=\rho x_{2}^{c *} .
$$

Observing the life-time budget constraint of a morning-leaving creditor and by the condition that $\rho x_{2}^{c *}=x_{2}^{c}$, we find the following: if $\rho\left(1+\gamma^{*}\right)>1$, a creditor's life-time budget (in both states) is maximized given the prices if $a=0$. Whereas if $\rho\left(1+\gamma^{*}\right)<1$, his life-time budget is maximized if $a=1$. Therefore, a creditor has incentive to lower his offering interest rate if $\rho\left(1+\gamma^{*}\right)>1$ to sell only to the afternoon producers and raise his offering interest rate if if $\rho\left(1+\gamma^{*}\right)<1$ to sell only to the morning producers. Only if $\rho\left(1+\gamma^{*}\right)=1$, the creditors are indifferent to the value of $a$, and they have no incentive to make a different offer. Therefore, the contingent IOU contract must have $1+\gamma=1 / \rho$, and a creditor's first-order condition becomes

$$
u_{1}\left(y_{1}^{c}\right)=\frac{p_{y}}{p_{x}}\left[(1-\alpha) u_{2}\left(x_{2}^{c}\right)+\frac{1}{\rho} \alpha u_{2}\left(x_{2}^{c *}\right)\right]
$$


Given that $1+\gamma=1 / \rho$, a morning producer solves the following maximization problem

$$
\begin{array}{cc}
\max _{x_{1}^{d}, x_{2}^{d}, k, b} & v\left(x_{1}^{d}, x_{2}^{d}\right) \\
\text { s.t. } \left.\quad p_{x}\left[f(k)+x-x_{1}^{d}\right]\right]-p_{y} k+(1-\rho)(1+\gamma) b=p_{x} x_{2}^{d} \\
x-x_{1}^{d} \geq 0 \\
p_{x}\left[f(k)+x-x_{1}^{d}\right]-p_{y} k-\rho(1+\gamma) b \geq 0
\end{array}
$$

The first-order conditions for the morning producers are

$$
\begin{aligned}
\left(x-x_{1}^{d}\right)\left(v_{1}\left(x_{1}^{d}\right)-v_{2}\left(x_{2}^{d}\right) \frac{1}{\rho}\right) & =0 \\
f^{\prime}(k) & =\frac{p_{y}}{p_{x}}
\end{aligned}
$$

From the complementary slack condition, it follows that $\rho=1$ is satisfied if and only if the liquidity constraint in unbinding.

An afternoon producer solves the following maximization problem:

$$
\begin{array}{cc}
\max _{x_{1}^{d *}, x_{2}^{d *}, k^{*}} & v\left(x_{1}^{d *}, x_{2}^{d *}\right) \\
\text { s.t. } & p_{x} F\left(k^{*}\right)+p_{x}\left(x-x_{1}^{d *}\right)-(1+\gamma) p_{y} k^{*}=p_{x} x_{2}^{d *} \\
x-x_{1}^{d *} \geq 0
\end{array}
$$

The first-order conditions for the afternoon producer's problem are:

$$
\begin{aligned}
\left(x-x_{1}^{d *}\right)\left(v_{1}\left(x_{1}^{d *}\right)-v_{2}\left(x_{2}^{d *}\right)\right) & =0 \\
F^{\prime}\left(k^{*}\right) & =(1+\gamma) \frac{p_{y}}{p_{x}}=\frac{1}{\rho} \frac{p_{y}}{p_{x}}
\end{aligned}
$$


The market clearing conditions are the same as in the main text.

Re-exam of proposition 1: There exists a mixed strategy Nash equilibrium, $\lambda \in(0,1)$ and $\rho \in(0,1)$. Moreover, no pure-strategy Nash equilibrium exists.

Proof. If $\lambda=0$, there is no morning producer. The discount rate in the resale market must be $\rho=0$ as no one buys the IOUs. If a debtor chooses to be a morning producer, he can make infinite profits in the resale market. Thus, we reach a contradiction.

If $\lambda=1$, there is no afternoon producer. All debts are paid in full in the first subperiod in the central island, that is $\rho=1$. It follows that $\gamma=0$. A debtor will choose to become an afternoon producer as the afternoon production yields higher return. Therefore, we reach a contradiction.

In a similar way, we can prove that $\rho \in(0,1)$.

Re-exam of proposition 2: In the decentralized economy, the optimal intraday rate is zero.

Proof. The proof is the same as in the main text.

Re-exam of proposition 3: In the economy with Diamond-Dybvig type creditors, (i) if the planner's resource constraint in the morning is nonbinding (Case 1), then setting $\rho=0$ (or $r=1$ ) implements the planner's allocation; (ii) if the planner's resource constraint in the morning is binding and the resource equals the consumption by morning-leaving creditors (Case 2), then setting $\rho=\frac{u_{2}\left(\hat{x}_{2}^{c *}\right)}{u_{2}\left(\hat{x}_{2}^{c}\right)}$ (or $\left.r=\frac{u_{2}\left(\hat{x}_{2}^{c}\right)}{u_{2}\left(\hat{x}_{2}^{c *}\right)}-1\right)$ implements the planner's allocation; (iii) if endowments are strictly less than consumption by morning-leaving creditors (Case 3), then no intra-day rate can implement the planner's allocation.

Proof. It is easy to see that in cases 1 and 2 of the planner's allocation, we can use the same intra-day rate policy and the tax-transfer scheme in the main text to achieve the planner's 
allocation in a decentralized economy.

In case 3 of the planner's allocation, we need to set $\rho=1$ to satisfy (26) in the planner's allocation. However, $\rho=1$ results in $x_{2}^{c}=x_{2}^{c *}$, which violates the planner's condition that $\hat{x}_{2}^{c}<\hat{x}_{2}^{c *}$. Therefore, the contingent planner does not achieve the planner's allocation in case 3 .

\subsection{Observable production choice (no hidden action)}

In this section, we assume that the production choice of the debtors are observable to the creditors. The creditors can charge different price for capital purchased by different type of producers. Let $p_{y}$ and $p_{y}^{*}$ be the prices of capital for the morning and afternoon producers, respectively.

The morning producer's optimization problem does not change. The afternoon producer's optimization decision results in

$$
\begin{aligned}
\left(x-x_{1}^{d *}\right)\left(v_{1}\left(x_{1}^{d *}\right)-v_{2}\left(x_{2}^{d *}\right)\right) & =0 \\
F^{\prime}\left(k^{*}\right)-\frac{p_{y}^{*}}{p_{x}} & =0
\end{aligned}
$$

Let $a$ and $a^{*}$ be redefined as the quantities of capital a creditor sells to morning and 
afternoon producers, respectively. A creditor solves the following problem:

$$
\begin{array}{cc}
\max _{y_{1}^{c}, a, a^{*}, x_{2}^{c}, x_{2}^{c *}, q} & (1-\alpha) u\left(y_{1}^{c}, x_{2}^{c}\right)+\alpha u\left(y_{1}^{c}, x_{2}^{c *}\right) \\
\text { s.t. } & p_{y} a+\rho p_{y}^{*} a^{*}=p_{x} x_{2}^{c} \\
p_{y} a+p_{y}^{*} a^{*}+(1-\rho) q=p_{x} x_{2}^{c *} \\
y=y_{1}^{c}+a+a^{*} \\
p_{y} a-\rho q \geq 0
\end{array}
$$

The first-order conditions result in

$$
\begin{aligned}
p_{y} & =\rho p_{y}^{*} \\
x_{2}^{c} & =\rho x_{2}^{c *} \\
x_{2}^{c} & =p_{y}\left(y-y_{1}^{c}\right) \\
u_{1}\left(y_{1}^{c}\right) & =\frac{p_{y}}{p_{x}}\left[(1-\alpha) u_{2}\left(x_{2}^{c}\right)+\frac{1}{\rho} \alpha u_{2}\left(x_{2}^{c *}\right)\right]
\end{aligned}
$$

The market clearing conditions are the same as in the main text.

The first-order conditions in the economy with no hidden action are the same as these in the economy with hidden action and contingent IOU contracts. As our propositions 1-3 hold in the economy with hidden action and contingent IOUs, they also hold here. With no hiddn action, creditors can sell capital at different prices. In equilibrium, the prices of capital must satisfy a non-arbitrage condition so that a creditor is indifferent to morning and afternoon producers. In an economy with hidden action, a contingent contract serves the same purpose: in equilibrium, creditors must be indifferent to the two types of producers. 
Although creditors cannot distinguish producers when they sell capital, they can vary the interest rate to attract a particular type to eliminate hidden action. In both economies, the results in the main text survive. In particular, if planner's allocation requires some morning production, no intra-day rate can achieve the planner's allocation in a decentralized economy. It is again because we do not have enough policy tools to match the three characteristics $(\lambda$, $k$, and $\left.k^{*}\right)$ in the planner's allocation. 